\title{
ESTIMATIVA DA ÁREA FOLIAR EM MILHARAL (1)
}

\author{
ANTONIO ROBERTO PEREIRA (2)
}

\section{RESUMO}

Num experimento com milho hibrido simples, conduzido no Centro Experimental de Campinas, em 1971/72, testou-se o uso de um fator área foliar, obtido numa repetiçāo, na estimativa da área foliar por planta nas demais repetiçōes. Utilizaram-se os hibridos simples HS1227 (tipo duro) e HS7777 (tipo dentado) cultivados em duas densidades de plantio: $42.000 \mathrm{e}$ 84.000 plantas por hectare. Não houve diferença estatística entre os valores observados e estimados. $O$ erro-padrão da estimativa, em todos os casos, foi menor que $10 \%$.

Termos de indexação: fndice de área foliar, fator área foliar; milho; análise de crescimento.

(1) Recebido para publicação em 10 de setembro de 1986.

(2) Seçăo de Climaiologia Agrícola, Instituto Agronónico de Campinas (IAC), Caixa Postal 28, 13001 Campinas (SP). 


\section{INTRODUÇÃO}

O indice de área foliar (IAF) de uma comunidade vegetal é dado pela relação entre a área foliar das plantas, considerando um só lado da folha, e a área do terreno por elas ocupado (WATSON, 1952). Diversos são os métodos de estimativa da área foliar (PEREIRA \& MACHADO, 1987), destacando-se a utilização de equaçōes que a relacionam com as dimensōes lineares da folha. As gramíneas, em geral, possuem folhas aproximadamente retangulares, cujas áreas são estimadas através do produto entre o comprimento, a maior largura e um fator de ajuste. O fator de ajuste, ou fator de forma, varia com a cultura, situando-se ao redor de 0,7. Esse método, utilizado por MONTGOMERY (1911), em milho, com fator igual a 0,75 , é hoje consagrado como padrão (FRANCIS et al., 1969; SILVA et al., 1974; PEARCE et al., 1975; MACHADO et al., 1982).

Numa comunidade vegetal, onde tanto fatores genéticos como ambientais afetam o crescimento $e$ o desenvoivimento das plantas, a variabilidade entre individuos exige coleta de 5 a 10 plantas por amostra (FRANCIS et al., 1969) para que a estimativa seja representativa da população. Uma planta de milho possui entre 10 e 15 folhas. Daí, pode-se avaliar o trabalho envolvido na mensuração da área foliar de uma única amostra.

Em plantas de milho, há estreita correlação entre a área foliar da planta $(Y)$ e a área da maior folha (X) (FRANCIS et al., 1969; PEARCE et al., 1975). Admitindo que a linha de regressão passe pela origer, $Y=b X, o$ coeficiente de regressão (b) representa o fator área foliar (FAF) de FRANCIS et al. (1969). Conhecendo-se o FAF de uma repetição, FRANCIS et al. (1969) sugerem sua utilização na estimativa da área foliar das demais repetições, medindo-se, nestas, apenas a área da maior folha das plantas.

O objetivo do presente trabalho foi testar o método proposto por FRANCIS et al. (1969), em dois hibridos simples, durante a estação de crescimento.

\section{MATERIAL E MÉTODOS}

O experimento foi conduzido num latossolo roxo do Centro Experimental de Campinas ( $23^{\circ} \mathrm{S}$., $47^{\circ} \mathrm{W}$., $\left.660 \mathrm{~m}\right)$, do Instituto Agronômico, no ano agrícola 1971/72 (SILVA et al., 1974). O delineamento experimental foi de blocos ao acaso, com dois híbridos simples de milho (HS7777 e HS1227) cultivados em duas densidades de plantio (42.000 e 84.000 plantas/hectare), com cinco repetiçōes. As parcelas eram de dez linhas de $10 \mathrm{~m}$ de comprimento, nos espaçamentos $0,6 \times 0,4 \mathrm{~m}$ e 1,2 $\times 0,4 \mathrm{~m}$, com duas plantas por cova. O HS7777 é do tipo dentado e o HS1227, do tipo duro. 
As medidas de comprimento $(C)$ e maior largura $(L)$ foram efetuadas em folhas de dez plantas competitivas de cada repetição, sendo a área de cada folha estimada pela equação $0,75 \times \mathrm{C} \times \mathrm{L}$. Determinou-se o fator área foliar em todas as repetições, e realizaram-se as amostragens aos 22,48 e 83 dias após a germinação.

\section{RESULTADOS E DISCUSSÃO}

Nas três amostragens, um total de 6.325 folhas tiveram suas áreas avaliadas. As médias e desvios-padrão do fator área foliar (FAF) obtidos nas três amostragens e nos quatro tratamentos encontram-se no quadro 1. Não houve diferença estatística entre os FAFs das repetiçōes. Portanto, o FAF de uma repetição pode, como sugerido por FRANCIS et al. (1969), ser utilizado para estimar a área foliar por planta nas outras repetiçōes. Os valores de FAF aumentaram com a idade da cultura, mas não diferiram estatisticamente nem entre os híbridos nem entre as densidades de plantio.

As correlaçōes entre área foliar/planta observada $(Y)$ e estimada $(\hat{Y})$ através do fator área foliar acham-se no quadro 2 . As correlaçōes incluem resultados das três amostragens. Os valores de $b$ indicam que as áreas estimadas $e$ observadas não se afastam significativarnente da linha 1:1, e que o coeficiente a é desprezivel. O erro-padräo da estimativa, em todos os casos, foi menor que $10 \%$.

QUADRO 1. Médias e desvios-padrāo do fator área foliar (FAF), em dois hibridos simples de milho, em duas populaçōes, em três amostragens

FAF

Tratamento

21 DAG (1)

$48 \mathrm{DAG}$

83DAG

HS1227

$42.000(2)$

84.000

$$
4,34 \pm 0,174
$$$$
4,45 \pm 0,149
$$

HS7777

42.000

84.000

$$
\begin{aligned}
& 4,15 \pm 0,123 \\
& 4,14 \pm 0,175
\end{aligned}
$$$$
6,07 \pm 0,264
$$$$
10,16 \pm 0,560
$$

$$
\begin{aligned}
& 5,98 \pm 0,321 \\
& 5,93 \pm 0,193
\end{aligned}
$$$$
9,86 \pm 0,102
$$$$
9,59 \pm 0,463
$$

(1) DAG = dias após germinação. (2) Plantas/hectare. 
QUADRO 2. Correlação entre área foliar observada $(Y)$ e estimada ( $\bar{Y})$, em dois hbridos simples de milho, em duas populaçōes $(n=60)$

\begin{tabular}{llll}
\hline Tratamento & $a$ & $b$ & $r^{2}$ \\
\hline
\end{tabular}

HS1227

\begin{tabular}{|c|c|c|c|}
\hline $42.000(1) \ldots \ldots$ & 44,2 & 0,9949 & 0,9966 \\
\hline $84.000 \ldots \ldots \ldots \ldots \ldots$ & 56,2 & 0,9951 & 0,9860 \\
\hline
\end{tabular}
HSi777

\begin{tabular}{|c|c|c|}
\hline 42.000 & 81,5 & 0,9897 \\
\hline $84.000 \ldots \ldots \ldots \ldots \ldots$ & 62,6 & 0,9954 \\
\hline
\end{tabular}

(1) Plantas/hectare.

SUMMARY

\section{ESTIMATING LEAF AREA IN CORN CROPS}

In a single cross corn hybrid experiment it was tested the use of a Leaf Area Factor, obtained in one replication, in estimating the leaf area per plant of the other replications. It was used the corn hybrids HS1227 (flint) and HS7777 (dent) grown at the densities of 42,000 and 84,000 plants per hectare. There was no statistical difference between the observed and the estimated values. The standard error of the estimation, in all cases, was lower than $10 \%$.

Index terms: leaf area index, leaf area factor, growth analysis, com.

\section{REFERÉNCLAS BIBLIOGRÁFICAS}

FRANCIS, C.A; RUTGER, J.N. \& PALMER, A.F.E. A rapid method for plant leaf area estimation in maize (Zea mays L.). Crop Science, 9:537-539, 1969.

MACHADO, E.C.; PEREIRA, A.R.; FAHL, J.l.; ARRUDA, H.V.; SILVA, W.J. \& TEIXEIRA, J.P.F. Análise quantitativa do crescimento de quatro variedades de milho em três densidades de plantio, através de funções matemáticas ajustadas. Pesquisa Agropecuária Brasileira, Braslia, 17:825-833, 1982.

MONTGOMERY, E.G. Correlation studies of corn. Annual report. Nebraska Agricultural Experiment Station, 24:108-159, 1911.

PEARCE, R.B.; MOCK, J.J. \& BAILEY, T.B. Rapid method for estimating leaf area per plant in maize. Crop Science, 15:691-694, 1975.

PEREIRA, A.R. \& MACHADO, E.C. Anâlise quantitativa do crescimento de comunidades vegetais. Campinas, Instituto Agronőmico, 1987. 33p. (Boletim técnico, 114)

SILVA, W.J.; MONTOJOS, J.C. \& PEREIRA, A.R. Análise de crescimento em dois hibridos simples de milho avaliada em duas densidades de populaçáo. Ciência e Cultura, São Paulo, 26:360-365, 1974.

WATSON, D.J. The physiological basis of variation in yield. Advances in Agronomy, 4:101-145, 1952. 